\title{
Scanning Electron Microscopic Observation of the Peritubular Zone in Dentin Sclerosis
}

\author{
by \\ Sohiti ISOKAWA, Yoshihisa TODA, Masahiko AJISAKA, Yoshinobu INOUE, \\ Takahiro SAITO and Sakae TSUCHIDA
}

\section{Introduction}

IsOKAWA, ToDA and KuBOTA[1] etched fractured human dentin surfaces with a weak acid and observed that a part of the peritubular zone persisted as a recognizable tubular structure. The inner hypomineralized layer (SHROFF, WILLIAMSON and BERTAUD [2], SHrofF et al.[3] and TAKUMA[4]) which appeared in the tubular structure was assumed to play an important role. IsoKAwA et al.[1] also presumed differences in acid etching according to the kind of teeth and the site of dentin of the same teeth.

In the present study, the influence of acid etching was studied in attrited and non-attrited teeth. It was concluded that the sclerosis of the dentinal tubules and the reprecipitation of crystals due to acid plays an important role in the formation of the tubular structure.

\section{Materials and Methods}

Five clinically caries free impacted third molars with no attrition and five caries free first and second molars with moderate attrition were used in the present study. Two teeth with moderate occlusal dentinal caries were also used as a part of the materials.

Immediately after extraction, the teeth were fixed with acetone. A longitudinal ground section of approximately $1-1.5 \mathrm{~mm}$ in thickness was obtained from about the

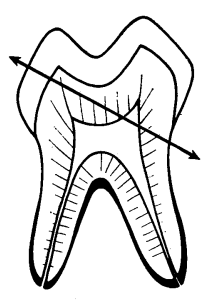

Fig. 1. Schematic illustration showing the line along which the dentin was fractured.

磯川宗七, 戸田善久, 鰺坂正彦, 井上嘉信, 斉藤高弘, 土田栄 Department of Anatomy, Nihon Univ. School of Dentistry, Tokyo (Director: Prof. Sohiti ISOKAWA) 
center of the tooth using a dental engine with a diamond disc. These ground sections were broken with forceps along the line indicated by the arrow in Fig. 1. One of the two dentin surfaces produced by the fracturing was not etched, while the other surface was treated for 90 seconds with $1 / 200 \mathrm{~N}$ formic acid. Each of the surfaces was covered with gold and studied with the scanning electron microscope.

One could observe on such a surface produced by fracturing, that some of the dentinal tubules extended from the pulp chamber side out to the dentinoenamel junction. Moreover, another advantage of this method was that it was also possible to observe the surface of both the non-etched and the etched portions of the same specimen.

\section{Results}

Each non-etched fractured dentin specimen of the attrited and non-attrited molars showed similar intertubular dentin, peritubular zones and dentinal tubular lumen (Figs. 2 and 3). This has already been observed by BoydE and LESTER[5], TODA et al.[6] and KuвотA et al.[7]. However, in the present study the peritubular zones of the dentin on the pulp side were not as well formed as those in the more peripheral parts of the dentin.

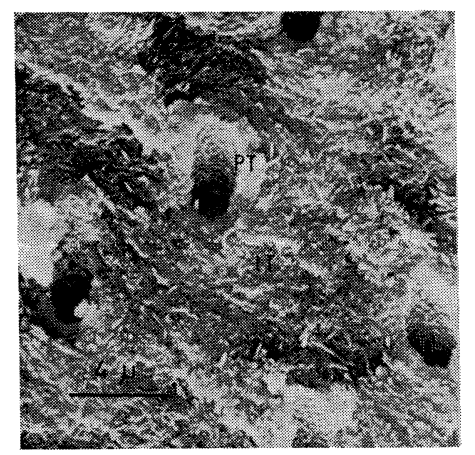

Fig. 2. Dentinal tubules, intertubular dentin and peritubular zones on the fractured dentin surface near the enamel of the non-etched attrited molar. PT: peritubular dentin, IT: intertubular dentin, TL: tubule-lumen.

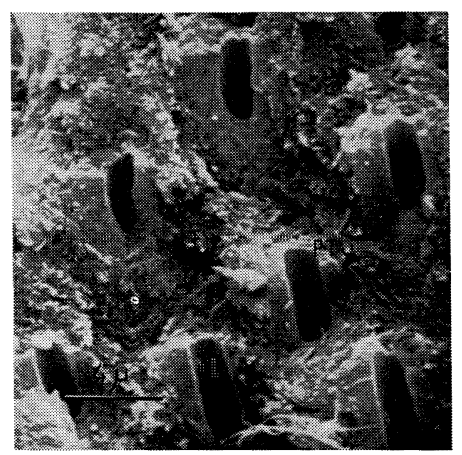

Fig. 3. Fractured surface showing the middle layer of the dentin of non-etched, nonattrited molar. The structures in figs. 2 and 3 look alike. PT: peritubular dentin, IT: intertubular dentin, TL: tubule-lumen.

When etching was applied to non-attrited and attrited molars, entirely different demineralized figures were obtained. On the fractured surface of the dentin in nonattrited molars, the surface was dissolved by acid, which gave a smooth appearance. The peritubular zone was more intensely influenced by acid than the intertubular dentin, appearing more concave than the intertubular dentin (Fig. 4). Moreover, as was pointed out by IsoKAWA et al.[1], the portion of peritubular zone adjacent to the intertubular dentin was more intensely influenced by acid than the rest of the peri- 


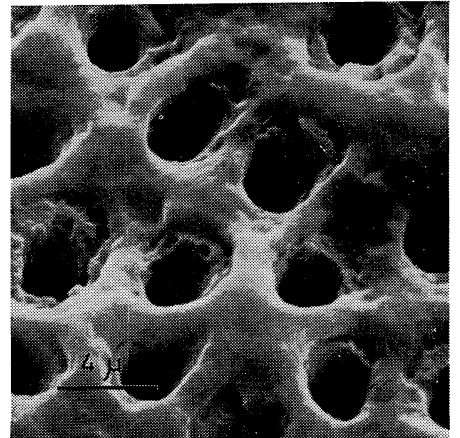

Fig. 4. Middle layer of the dentin of a nonattrited molar showing an etched fractured surface with more intense demineralization in the peritubular zone than in the intertubular dentin.

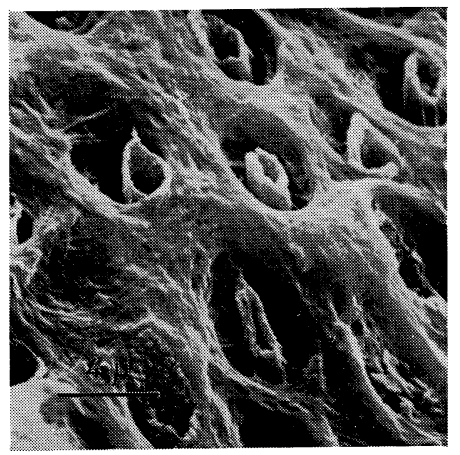

Fig. 6. The tubular structure of the fractured surface of the attrited molar dentin near the enamel is brought out by etching.

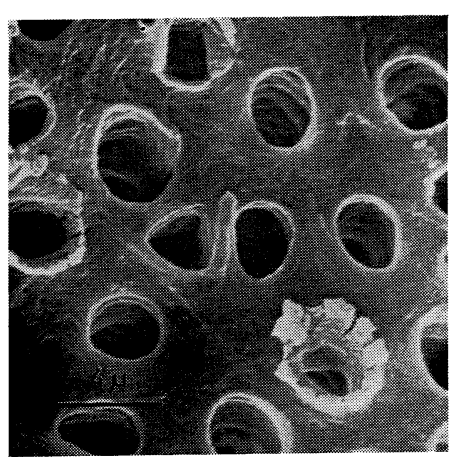

Fig. 8. Etched attrited molar dentin near the pulp showing there is scarcely any of the peritubular zone remaining.

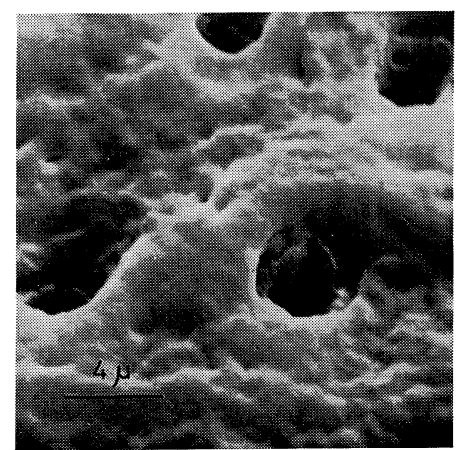

Fig. 5. Etched specimen showing scarcely remaining peritubullar zones of a nonattrited molar dentin near the pulp.

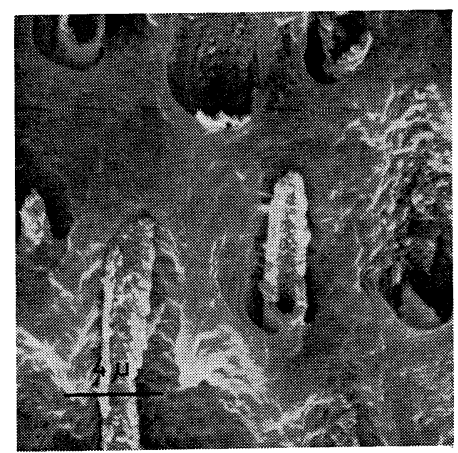

Fig. 7. Tubular structures seen in the dentinal tubules of the middle layer of an attrited molar dentin brought out by etching.

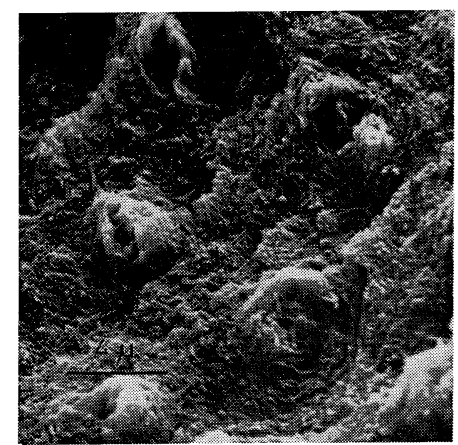

Fig. 9. Peritubular structures seen in the dentinal tubules of the unetched fractured surface of the soft dentin under the caries cone. 
tubular zone. In the portion of the dentinal tubule close to the pulp cavity, scarcely any remaining peritubular zone was noted in many cases (Fig. 5). In the specimens obtained from the non-etched, attrited molars, no tubular structure similar to that reported by IsoKAWA et al.[1] could be found in the dentinal tubules.

The acid produced complicated changes on the fractured surface of the dentin of the attrited molar. The tubular structure (IsoKawA et al.[1]) appeared in many dentinal tubules except for those close to the pulp cavity. It was impressive that the tubular structure appeared in groups of dentinal tubules in certain areas rather than as dentinal tubules scattered at random (Fig. 6). However, among the groups of dentinal tubules with a tubular structure there were some scattered dentinal tubules without them and also without a peritubular zone. Between the periphery of the tubular structure and the intertubular dentin, a space was found, probably representing an almost complete dissolution of the peritubular zone. Occasionally, a fiber-like structure was found in this space, running between the intertubular dentin and the tubular structure (IsoKAwA et al.[1]). The external wall of the tubular structure facing the space was rather smooth, but the internal wall appeared to be lined with granular particles of irregular size (Fig. 7).

In the dentinal tubules of the attrited molar close to the pulp cavity, scarcely any tubular structure appeared following the action of acid. These dentinal tubules apparently had lost all of their peritubular zone through demineralization (Fig. 8). However, a structure apparently related intimately with the tubular structure was found in some specimens.

The non-etched specimen from the molar teeth with dentinal caries, showed dentinal tubules in the less demineralized zone of the deeper layer of the caries cone. One could also see a structure corresponding to the aforementioned tubular structure (Fig. 9).

\section{Discussion}

In dental caries, more extensive demineralization takes place in the intertubular dentin than in the peritubular zone (JOHANSEN and PARKs[8], TAKuma and KuRAHAShi[9], SARnAT and MASSLER[10]). When a weak acid, used experimentally, acts on dentin, the peritubular zone was said to be less resistant to the acid (Selvig[11, 12], IsoKAWA et al.[1]). In the present study, the resistance of the peritubular zone to acid was weak. In the non-attrited third molar, the peritubular zone close to the intertubular dentin was more readily soluble by acid than that close to the lumen of the dentinal tubules. However, our unpublished study using the scanning electron microscope on the fractured surface of the dentin of the non-attrited third molar showed that the peritubular zone had completely disappeared when the time of etching with $1 / 200 \mathrm{~N}$ formic acid reached 180 seconds. In the attrited molar subjected to etching for 90 seconds, the peritubular zone except for the tubular structure itself had been completely dissolved. This might indicate that aging of the teeth influenced the acid resistance in the peritubular zone.

IsoKAwA et al.[1] described the appearance of a tubular structure in the dentinal tubules of a fractured dentin surface treated with a weak acid. In the present study, 
no such tubular structure was noted in the non-attrited third molar. In attrited first and second molars, however, many tubular structures were visible. IsOKAwA et al. assumed that the inner hypomineralized layer (SHrofF et al.[2, 3], TAKUMA[4]) seen in the peritubular zone and the needle-like crystal (SeLVIG[11]) appearing in the inside wall of the dentinal tubules after demineralization appeared to be an important featrue in the appearance of a tubular structure.

On the other hand, it has long been well known from histologic, electron microscopic and historadiographic studies that mineral crystals are deposited intratubularly in the dentinal tubules of sclerotic dentin in attrited teeth (Feller[13], Beust[14, 15], Bodecker and Applebaum[16], Bradford[17], Blake[18], Nalbandian, Gonzales and Sognnaes[19], Harcourt[20], Toda et al.[21], IsoKawa et al.[22], Takuma and EDA[23]). In the transparent root dentin and translucent zone seen in dental caries, mineral deposition was noted in the cytoplasmic processes of odontoblasts and walls of the dentinal tubules (Bennett[24], Feiler[13], Beust[25], Blake[26], Frank[27], Nalbandian et al.[19], Takuma and Kurahashi[9], Sarnat and Massler[10]). Such a mineral deposit, moreover, is said to be resistant to caries. TAKUMA and EDA[23], furthermore, pointed out that there was greater resistance to acid by the mineral deposits within the dentinal tubules than that in the peritubular zones.

These previous studies, and the present study, that is, the observations obtained from the less demineralized dentin around the caries cone and the absence of a tubular structure in the non-attrited third molar, emphasize the fact that the appearance of tubular structures in the dentinal tubules should be considered to be a result of the secondary physiological changes in the dentinal tubules.

If the appearance of the tubular structure is ascibed to the demineralized products in the sclerosed dentin tubules, the appearance of great rhomboidal caries crystals seen intratubularly in dental caries (Helmcke[28], Lenz[29], HöHling[30], Frank, WolfF and Gutmann[31], VAhL, HöHLing and Frank[32]) and the greater resistance to acid of these crystals rather than those of crystals in normal dentin (JoHANSEN[33], Takuma and Kurahashi[9], Sarnat and Massler[10]) deserve further attention. Similar phenomena, that is, the appearance of large rhomboidal crystals with greater resistance to acid were observed in the sclerotic dentin by NALBANDIAN et al.[19] and Selvig[12]. Takuma and Kurahashi[9] also observed the sclerotic root dentin and translucent zone of caries. This mineral with greater resistance to acid proved to be whitlokite (VAHL et al.[32], FranK et al.[31], Selvig[11]).

Based on the present study showing the appearance of tubular structures and the complete dissolution of the surrounding peritubular zone after treatment with $1 / 200$ $\mathrm{N}$ formic acid, an intimate relationship between the appearance of the tubular structure and reprecipitation of acid resistant crystals described above might be suspected. The fact that the inside surface of the tubular structure is lined with granular material of irregular size should be specifically emphasized as a possible crystal reprecipitation process.

It is a fact that the tubular structure can seldom be found in the portion of dentinal tubules close to the pulp of the attrited teeth. There is a failure of appearance of the tubular structure at random in the dentinal tubules in other parts of the dentin. On these facts and the assumption of a concentrated appearance of the tubular structures 
in dentin sclerosis, might this suggest a relationship between this phenomenon and sclerosis.

\section{Summary}

Scanning electron microscopic observations were carried out on the fractured etched and unetched surfaces of the dentin of non-attrited third molars and moderaely attrited first and second molars. In the dentin of non-attrited molars, increased solubility of the peritubular but not of the intertubular detnin was demonstrated. However, as the result of the deminerlization a tubular structure was not seen. The tubular structure appeared in many of the dentinal tubules in portions other than close to the pulp cavity in attrited molars. In the dentin of attrited molars, the peritubular zone around the tubular structure was completely dissolved. While the external wall of the tubular structure was rather smooth, the internal surface appeared granular. Based on these observations the etching effect on the peritubular zone was found to be different in non-attrited and attrited molars. The tubular structure seen in the molar with attrition is apparently related to the aging reaction of the dentinal tubules, and its appearance is influenced by the important action of the reprecipitation of the crystal dissolved at the time of etching.

\section{References}

[1] Isokawa, S., Toda, Y. and Kubota, K.: A scanning electron microscopic observation of etched peritubular dentin. Archs. oral Biol. 1970, (in press).

[2] Shroff, F. R., Williamson, K. I. and Bertaud, W. S.: Electron microscope studies of dentine, The true nature of the dentinal canals. Oral Surg. 7: 662-670, 1954.

[3] Shroff, F. R., Williamson, K. I., Bertaud, W. S. and Hall, D. M.: Further electron microscope studies of dentine. The nature of the odontoblast process. Oral Surg. 9: 432-443, 1956.

[4] Takuma, S.: Ultrastructure of dentinogenesis. Structural and chemical organization of teeth, Vol. I, 325-370, 1967, (edited by Miles, A.E.W.) Academic Press, New York.

[5] Boyde, A. and Lester, K. S.: An electron microscope study of fractured dentinal surfaces. Calc. Tiss. Res. 1: 122-136, 1967.

[6] Toda, Y., Sato, H., Yoshie, T., Mikami, K., Yamakawa, H. and Shimoda, M.: Preliminary scanning electron microscopic observations of human enamel and dentin. Nihon Univ. dent. $\mathbf{J}$. 43: 156-159, 1969, (Japanese).

[7] Kubota, K., Ajisaka, M., Inoue, Y., Yamaguchi, S. and Hasegawa, I.: Scanning electron microscopic observation of longitudinally sectioned dentinal tubules. J. Nihon Univ. Sch. Dent. 11: 140-143, 1969.

[8] Johansen, E. and Parks, H. F.: Electron-microscopic observations on soft caries human dentin. J. dent. Res. 40: 235-248, 1961.

[9] TAKuma, S. and Kurahashi, Y.: Electron microscopy of various zones in a carious lesion in human dentin. Archs. oral Biol. 7: 439-453, 1962.

[10] Sarnat, H. and Massler, M.: Microstructure of active and arrested dentinal caries. J. dent. Res. 44: 1389-1401, 1965.

[11] Selvig, K. A.: Ultrastructural changes in human dentine exposed to a weak acid. Archs. oral Biol. 13: 713-734, 1968.

[12] Selvig, K. A.: Effect of fluoride on the acid solubility of human dentine. Archs. oral Biol. 13: 1297-1310, 1968.

[13] Feiler, E.: Die Transparenz des Zahnbeins. Zeitschr. f. Stomat. 21: 595-614, 1923.

[14] Beust, T. B.: Posteruptive changes in the maturation of teeth. J. Amer. dent. Ass. 18: 21862192, 1931. 
[15] Beust, T. B.: Inflammatory zones in the dentine. J. dent. Res. 13: 399-405, 1933.

[16] Bodecker, C. F. and Applebaum, E.: Metabolism of the dentin; its relation to dental caries and to the treatment of sensitive teeth. Dent. Cosmos 73: 995-1009, 1931.

[17] Bradford, E. W.: The maturation of the dentine. Brit. dent. J. 105: 212-216, 1958.

[18] Blake, G. C.: The peritubular translucent zones in human detine. Brit. dent. J. 104: 57-64, 1958.

[19] Nalbandian, J., Gonzales, F. and Sognnaes, R. F.: Sclerotic age changes in root dentin of human teeth as observed by optical, electron, and X-ray microscopy. J. dent. Res. 39: 598-607, 1960.

[20] Harcourt, J. K.: Further observations on the peritubular translucent zone in human dentine. Austral. dent. J. 9: 387-392, 1964.

[21] Toda, Y., Tsuruoka, Y., Wada, N., Tsubouchi, M., Hasegawa, T. and Nishihara, T.: Historadiography of exposed dentinal tubules of human dentin. Nihon Univ. dent. J. 40:541547, 1966, (Japanese).

[22] Isokawa, S., Satomura, I., Misu, T., Hasegawa, T. and Honda, H.: Some historadiographs of human dentin structures. J. Nihon Univ. Sch. Dent. 8: 191-197, 1966.

[23] Takuma, S. and EdA, S.: Structure and development of the peritubular matrix in dentin. J. dent. Res. 45: 683-692, 1966.

[24] BennetT, M. J.: Die Beschaffenheit der Transparenz-zone der Zahnkaries. Corr. -Blatt f. Zahnarzt. 363-364, 1895.

[25] Beust, T. B.: Resistance to caries. J. dent. Res. 11: 619-632, 1931.

[26] Blake, G. C.: An experimental investigation into the permeability of enamel and dentine with reference to its relation to dental caries. Proc. Roy. Soc. Med. Sect. Odont. 51: 678-682, 1958.

[27] Frank, R. M.: Electron microscopy of undecalcified sections of human adult dentine. Archs. oral Biol. 1: 29-32, 1959.

[28] Helmcke, J. -G.: Elektronenmikroskopische Strukturuntersuchungen an gesunden und kranken Zähnen. Dtsch. Zahnärztl. Zeitschr. 10: 1461-1478, 1955.

[29] LenZ, H.: Electronenmikroskopischer Nachweis der Dentin-Veränderungen durch Karies. Dtsch. Zahn -Mund u. Kieferhk. 22: 24-33, 1955.

[30] HöHLing, H. -J.: Elektronenmikroskopische Untersuchungen am gesunden und kariösen Dentin mit Hilfe der Abdruckmethode und der Schnittmethode an kompakter, nichtentminerali zierter Substanz. Zeitschr. f. Zellforsch. 53: 192-200, 1961.

[31] Frank, R. M., Wolff, E. and Gutmann, E.: Microscopie electronique de la carie au niveau de la dentine humaine. Archs. oral Biol. 9: 163-179, 1964.

[32] Vahl, J., Höhling, H. J. and Frank, R. M.: Elektronenstrahlbeugung an rhomboedrisch ausshenden Mineralbildungen in kariösen Dentin. Archs. oral Biol. 9: 315-320, 1964.

[33] Johansen, E.: Electron microscopic and chemical studies of carious lesions with reference to the organic phase of affected tissues. Ann. N.Y. Acad. Sci. 131: 776-785, 1965. 